\title{
Relapsing polychondritis, a rare cause of valvulopathy: A review of the medical literature
}

\section{Policondritis recurrente, una rara causa de valvulopatía: revisión de las publicaciones médicas}

\author{
Eduardo Bahena-López ${ }^{*}$ and Jorge Loya-Centurión ${ }^{2}$ \\ ${ }^{1}$ Department of Hemodynamics; 'Department of Clinical Cardiology, Instituto Nacional de Cardiología "Ignacio Chávez," Mexico City, Mexico
}

\begin{abstract}
Relapsing polychondritis $(R P)$ is an inflammatory disease that involves cartilaginous structures predominantly in the nose, ears, and respiratory tract. Cardiovascular involvement is not common. Despite this, they are the second cause of death in patients with RP. The structures usually affected by this disease are the heart valves, with regurgitation being the most common valvulopathy. We present the case of a patient without the previous diagnosis of RP who was referred to our institute with heart failure secondary to aortic regurgitation, initially attributed to endocarditis.
\end{abstract}

Key words: Relapsing polychondritis. Valvular disease. Aortic regurgitation. Mexico.

\section{Resumen}

La policondritis recurrente (PR) es una enfermedad inflamatoria que afecta a estructuras cartilaginosas, predominantemente las que se encuentran en nariz, pabellones auriculares y vías respiratorias. Las manifestaciones cardiovasculares son poco comunes; sin embargo, son la segunda causa de mortalidad en pacientes con PR. Unas de las estructuras afectadas casi siempre en la PR son las estructuras valvulares y la valvulopatía más común es la insuficiencia aórtica (IA). A continuación se presenta el caso de una paciente sin diagnóstico previo de PR a quien se refirió a este instituto por insuficiencia cardíaca secundaria a $I A$, atribuida en un principio a endocarditis.

Palabras clave: Policondritis recurrente. Enfermedad valvular. Insuficiencia aórtica. México.

\section{Introduction}

Thirty-eight-year-old woman presented with a history of chronic non-specific ulcerative colitis (CNUC) under treatment with meclizine. She presented with clinical symptoms characterized by asthenia, adynamia, $40^{\circ} \mathrm{C}$ fever with chills, in addition to liquid bowel movements with traces of bleeding, tenesmus, and incontinence.
She was hospitalized in another institution where a heart murmur was detected. Transthoracic echocardiogram (TTE) showed serious aortic insufficiency (AI). Due to these findings, she was transferred to National Institute of Cardiology of Mexico. On admission, clinical data consistent with severe Al were found, including positive Landolfi's sign, Corrigan's pulse, precordium with aspirational, holodiastolic murmur in accessory

\section{Correspondence:}

*Eduardo Bahena-López

E-mail: eduardobahena@comunidad.unam.mx DOI: 10.24875/ACME.M20000112
Date of acceptance: 19-11-2019
Available online: 04-09-2020

Arch Cardiol Mex (Eng). 2020;90(2):173-176
www.archivoscardiologia.com

Arch Cardiol Mex (Eng). 2020;90(2):173-176
www.archivoscardiologia.com license (http://creativecommons.org/licenses/by-nc-nd/4.0/). 
aortic focus irradiating to the apex, extremities with wide peripheral pulses, positive Lyan and Quincke signs, in addition to left auricle with augmented size, edema, erythema, and tenderness.

The TTE revealed dilated left ventricle with ejection fraction of $50 \%$, right ventricle with preserved systolic function, trivalve aortic valve with left coronary leaflet prolapse, and aortic root dilation that caused severe $\mathrm{Al}$ (Fig. 1A and B). The approach was completed with transesophageal echocardiogram, which showed low probability of endocarditis and corroborated the previously described TTE findings (Fig. $1 \mathrm{C}$ and D).

Due to her previous history of CNUC, she was evaluated by the Gastroenterology Department, where a colonoscopy identified CNUC-secondary pancolitis. In view of the apparent presence of auricular chondritis, she was also assessed by the Rheumatology Department due to suspected relapsing polychondritis (RP). RP diagnosis was established by the presence of three McAdam criteria: auricular chondritis, nasal chondritis, and audiovestibular damage (left unilateral hearing loss corroborated by audiometry). Treatment with hydrocortisone and methotrexate was started. Due to the presence of $\mathrm{Al}$, aortic valve exchange operation was proposed, but the patient rejected the procedure. She was discharged with treatment based on prednisone and methotrexate and continued on follow-up by the outpatient services. In the follow-up visit 2 months after her discharge, improvement of the auricular inflammatory process was noticed, as well as cardiovascular symptoms' improvement (NYHA functional Class I).

\section{Discussion}

$\mathrm{RP}$ is a systemic inflammatory disease characterized by repetitive episodes of inflammation of cartilaginous structures and proteoglycan-rich tissues (eyes, heart, and blood vessels). Its annual incidence is 3.5 cases per million population, with peak incidence at between 30 and 55 years of age ${ }^{1}$. The cause is unknown, although there appears to be some genetic susceptibility. A relationship between RP and major histocompatibility complex Class II has been described, specifically with human leukocyte antigen (HLA)-DR4. Humoral immunity plays an important role in pathophysiology through the production of autoantibodies, especially against type II collagen. Production of autoantibodies against type IX and XI collagen, as well as matriline 1 and extracellular matrix proteins present in cartilage, is also identified ${ }^{2}$. Another relevant pathophysiological mechanism is an elevation of pro-inflammatory cytokines involved in macrophage, monocyte, and leukocyte activation in patients with RP, which suggests impairment of cellular immunity ${ }^{3}$, which appears to be directed against type II collagen as well ${ }^{4}$.

RP most common clinical manifestations are auricular (36-81\%) and nasal (29-54\%), with the former being the most prevalent initial manifestation. There are also cardiovascular, renal, and neurological manifestations, which are less common ${ }^{1}$. Cardiovascular manifestations include aortitis, aortic aneurysms, valvulopathies (aortic or mitral regurgitation), conduction system disorders, and pericarditis, among others ${ }^{5,6}$.

Cardiovascular complication-related mortality is the second most important cause of death after of laryngotracheal complications. Within these complications, aortic compromise stands out, which has been documented in 5\%-10\% of individuals with RP. Aortic lesions can be asymptomatic at early stages, and there appears to be certain selectivity for the thoracic aorta $(82-92 \%)$, and up to one-third of patients present with thoracic and abdominal aorta involvement. The most common aortic abnormalities described in these patients are isolated aortic aneurysms and aortitis. The presence of chronic aortitis is likely to be part of the pathophysiology of aortic aneurysm development ${ }^{5}$. Based on the above, the most common cardiovascular clinical manifestations are attributed to aortic regurgitation secondary to aortic root dilation ${ }^{2,7}$.

RP diagnosis is established using the McAdam criteria; at least three criteria are required for the diagnosis to be established. These criteria include auricular chondritis, non-erosive polyarthritis, nasal chondritis, ocular inflammation (conjunctivitis, keratitis, uveitis, and scleritis), respiratory tract chondritis (larynx or trachea), and cochlear or vestibular alterations (hearing loss, tinnitus, and vertigo) ${ }^{8}$.

There is no specific laboratory work-up for polychondritis diagnosis. When there is diagnostic doubt, auricular biopsy is useful to corroborate the diagnostic suspicion.

The use of positron emission tomography/computed tomography with 18F-fluorodeoxyglucose is useful for diagnosis when clinical presentation lacks typical clinical manifestations, and uptake increase is identified in compromised sites, including the aorta ${ }^{2}$. In addition, it is useful during follow-up to assess the response to immunosuppressive treatment ${ }^{9}$.

For the treatment of RP, immunosuppressive and immunomodulatory drugs are commonly used, but none of them has been shown to modify the natural evolution of the disease. Factors such as compromised organs, severity, and duration of activity should be taken into 


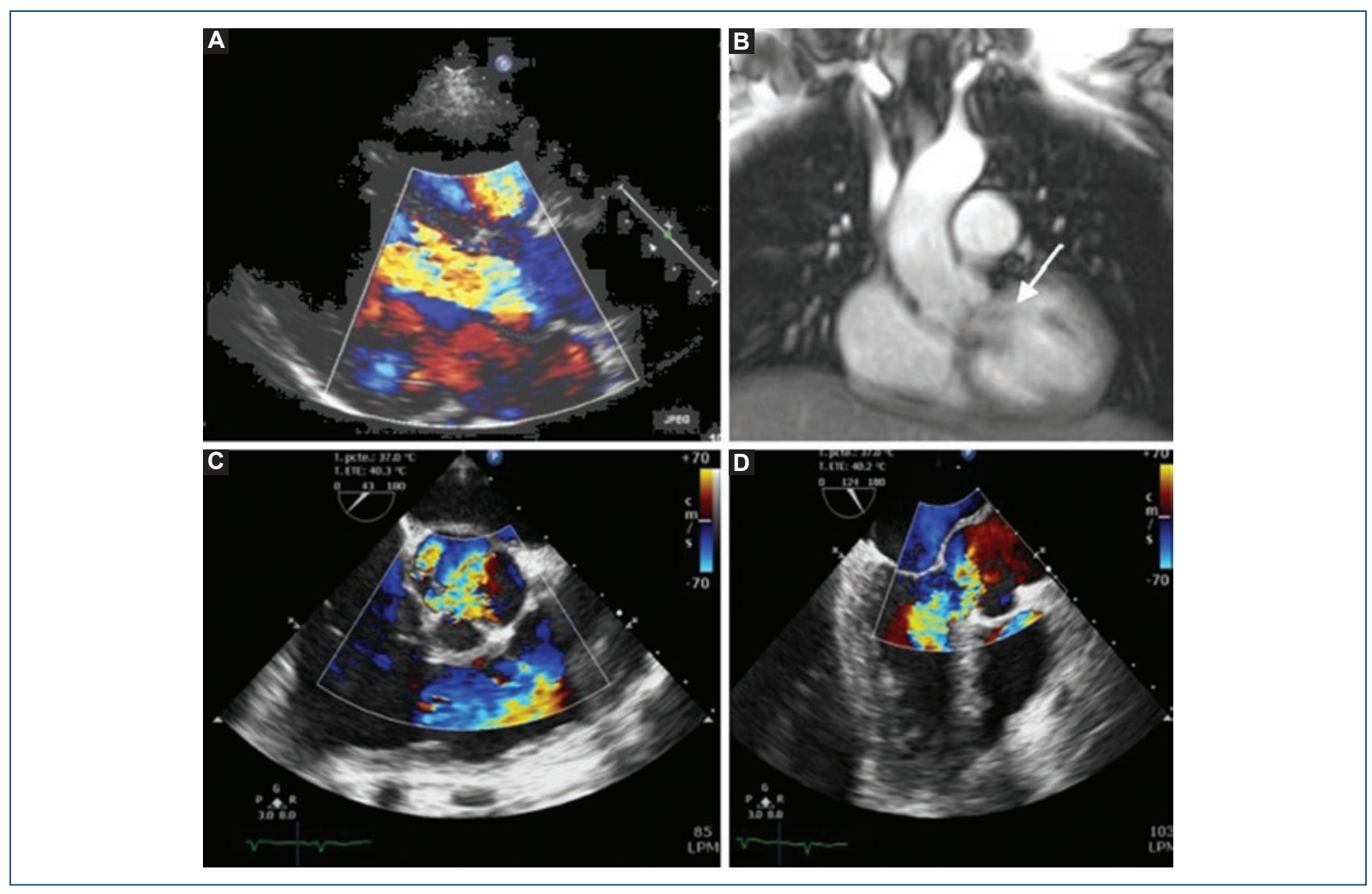

Figure 1. A: Transthoracic echocardiogram: long parasternal axis with color Doppler technique showing heart failure. B: Magnetic resonance imaging showing regurgitant aortic flow (arrow). C and D: TE-Echo color Doppler images showing aortic insufficiency flow.

account when making therapeutic decisions. Treatment with glucocorticoids is the cornerstone of treatment of this disease. In cases, where the disease is moderate or serious, with risk of damage to compromised organs, the use of combined treatment is indicated, with addition of cyclophosphamide, azathioprine, or methotrexate to the glucocorticoid treatment. If despite this, an adequate treatment response is not obtained; biological agents such as tumor necrosis factor-alpha antagonists can be prescribed (infliximab, etanercept, and adalimumab). Other biological compounds that are administered in the treatment of RP such as tocilizumab (anti-interleukin-6 antibody) and abatacept (T-cell activation inhibitor) have been shown to be effective for the treatment of RP in some case series.

Indications for surgical treatment and ideal time to practice an intervention are controversial, given that surgical treatment entails multiple post-surgical complications due to the high risk of early prosthetic dehiscence and aneurysm recurrence due to tissue friability caused by recurrent inflammation, even in patients with mild disease ${ }^{5}$. Due to this, some authors recommend ascending aorta replacement whenever an aortic valve change is performed in patients with $\mathrm{RP}^{10}$.

During periodic follow-up of RP patients, cardiovascular compromise should be directly monitored, given that it does not only occur during the acute inflammatory disease phase, but it can occur even in asymptomatic patients ${ }^{5}$.

\section{Conclusion}

RP cardiovascular manifestations are the second leading cause of death in patients with this disease. Al is the most common valvular disease in RP and treatment consists of immunosuppressants to decrease inflammation and perform a valve exchange operation. Surgical treatment entails multiple complications due to tissue friability caused by recurrent inflammation.

\section{Funding}

The authors did not receive any type of funding of any organism. 


\section{Conflicts of interest}

This research has not received any specific grant from public or commercial sector agencies or non-profit entities.

\section{Ethical disclosures}

Protection of people and animals. The authors declare that no experiments were performed on humans or animals for this investigation.

Confidentiality of data. The authors declare that they have followed the protocols of their work center on the publication of patient data.

Right to privacy and informed consent. The authors have obtained informed consent from the patients and/or subjects referred to in the article.

\section{References}

1. Pallo PAO, Levy-Neto M, Pereira RMR, Shinjo SK. Relapsing polychondritis: prevalence of cardiovascular diseases and its risk factors, and general disease features according to gender. Rev Bras ReumatolEngl Ed 2017;57(4):338-45.

2. Mathian A, Miyara M, Cohen-Aubart F, Haroche J, Hie M, Pha M, et al. Relapsing polychondritis: a 2016 update on clinical features, diagnostic tools, treatment and biological drug use. Best Pract Res ClinRheumatol 2016;30(2):316-33.

3. Stabler T, Piette JC, Chevalier X, Marini-Portugal A, Kraus VB. Serum cytocine profiles in relapsing polychondritis suggest monocyte/macrophage activation. Arthritis Rheum 2004;50(11):3663-7.

4. Buckner JH, Van Landeghen M, Kwok WW, Tsarknaridis L. Identification of type II collagen peptide 261-273-specific T cell clones in a patient with relapsing polychondritis. Arthritis Rheum 2002;46(1):238-44.

5. Del Rosso A, Petix NR, Pratesi M, Bini A. Cardiovascular involvement in relapsing polychondritis. Semin Arthritis Rheum 1997;26:840-844

6. Kingdon J, Roscamp J, Sangle S, D'Cruz D. Relapsing polychondritis: a clinical review for rheumatologist. Rheumatology (Oxford) 2018;57(9):1525-1532.

7. Le Besnerais M, Amaud L, Boutémy J, Bienvenu B, Lévesque H, Amoura Z, et al. Aortic involvement in relapsing polychondritis. Joint Bone Spine 2018:85(3):345-51.

8. McAdam LP, O'Hanlan MA, Bluestone R, Pearson CM. Relapsing polychondritis: prospective study of 23 patients and a review of the literature. Medicine (Baltimore) 1976

9. Lei W, Zeng H, Zeng DX, Zhang B, Zhu YH, Jiang JH, et al. FDG PETCT as a powerful tool for diagnosing and monitoring treatment outcomes of relapsing polychondritis. Eur J Nucl Med Mol Imaging 2018;45(4):669-70.

10. Lang-Lazdunski $L$, Pansard $Y$, Hvass $U$. Aortic valve replacement in relapsing polychondritis. J Thorac Cardiovasc Surg 1997;114:131-2. 